\title{
Research on a widely applicable function expression of the dry-wet bulb coefficient through deviation control theory
}

\author{
Hong-ming Feng ${ }^{1}$,Qiang-sheng Feng ${ }^{2,}{ }^{*}$,Hao-xin Yan $^{3}$, Ping Zhou ${ }^{4}$, and Xiao-yin Huang ${ }^{4}$ \\ ${ }^{1}$ Zhejiang textile \& fashion vocational and Technical College ,NingBo, ZheJiang 315211, China \\ ${ }^{2}$ Zhejiang China Tobacco Industrial Co., Ltd, NingBo, ZheJiang 315000, China \\ ${ }^{3}$ Trane Air Conditioning System (China) Co.ltd,ShangHai 200000,China \\ ${ }^{4}$ Yunnan Agricultural Univcrsity, KunMing, YunNan 650201, China
}

\begin{abstract}
Relying on the experimental data, by using the theory of error control and function approximation to establish new wet and dry bulb coefficient $\widehat{A}\left(v, t_{a}\right)$. Through searching method and Iterative approximation, it finds an approximation function whose figure is closer to "experimental data" than previous one did. Hence, it increases the measurement accuracy of relative humidity by the wet and dry bulb method under the condition of the relative humidity in the range of $10^{\circ} \mathrm{C} \leq \mathrm{t} \leq 70^{\circ} \mathrm{C}$, air flow rate $0.1 \mathrm{~m} / \mathrm{s} \leq \mathrm{v} \leq 4 \mathrm{~m} / \mathrm{s}$, and relative humidity $30 \% \leq \mathrm{U} \leq 90 \%$.
\end{abstract}

\section{Foreword}

In modern industry, agricultural production, meteorology, environmental protection, national defense, scientific research, aerospace and other fields, the control requirements of relative humidity have become more common and important technical support. Moreover, the accurate standard of relative humidity control is getting stricter, especially in food, medicine, tobacco, textile and some other industries. It puts forward higher precision requirements of relative humidity control in high temperature environment to ensure the product quality and improve the product performance.

Wet and dry bulb method is a classical, commonly used and simple method. This method used to calculate the relative humidity indirectly by measuring the temperature and speed. Measurement of temperature and speed has been mature technology, hence, this method has more stable and reliable performance, good maintainability, and low cost compared with other measuring methods [1]. It is very important to improve the accuracy of relative humidity measurement by wet and dry bulb method in high temperature environment.

\section{Theory of measuring relative humidity by dry wet bulb method}

Relative humidity refers to the percentage of the actual partial pressure of water vapor in wet air and the saturated partial pressure of water vapor at the same temperature. The wet and dry bulb method measures the dry bulb temperature, the wet bulb temperature, the smaller the deviation degree (D.D), and the flow speed of the wet air to find out the relative humidity through formula (1) or figure table. The measurement device is simple, it consists of two thermometers with the same specification. One is called dry bulb thermometer, which is used to measure the ambient temperature. Its indication is noticed as $t_{a}$, the other is wrapped by wet gauze, a connected with the water container, which is called wet bulb thermometer. Its indication is noticed as $t_{w}$. At the same time, the velocity of wet air flow is measured by anemometer, which is used for the relative humidity calculation.

The measuring principle: the water of the wet gauze covered on the warm bubble absorbs the heat in the wet air and then evaporates continuously, which changes the water from liquid state to gas state, reducing the temperature of the wet ball. In this way, the evaporation rate of water in the wet bulb and the moisture content in the surrounding wet air form a certain functional relationship - the classical formula of relative humidity measured by the dry wet bulb method: August apzohn dry wet bulb equation [2-3].

$$
U=\frac{E_{w}-A P_{a}\left(t_{a}-t_{w}\right)}{E_{s}} \times 100 \%
$$

Among all symbols in the equation: $U$ equals relative humidity (\%), $\mathrm{t}_{\mathrm{a}}$ stands for dry bulb temperature $\left({ }^{\circ} \mathrm{C}\right), \mathrm{t}_{\mathrm{w}}$ stands for wet bulb temperature $\left({ }^{\circ} \mathrm{C}\right), \mathrm{E}_{\mathrm{w}}$ is the partial pressure of saturated water vapor at the wet bulb temperature $(\mathrm{Pa}), \mathrm{E}_{\mathrm{s}}$ is the partial pressure of saturated water vapor at the dry bulb temperature $(\mathrm{Pa}), \mathrm{A}$ is the coefficient of dry wet bulb $\left(\mathrm{s} / \mathrm{m}{ }^{\circ} \mathrm{C}\right), \mathrm{P}_{\mathrm{a}}$ is the total pressure of the measured gas $(\mathrm{Pa})$.

When it comes to the spatial measurement of open low altitude areas, $\mathrm{P}_{\mathrm{a}}$ usually equals atmospheric pressure $101325 \mathrm{~Pa}$, when the altitude of measurement is higher than $100 \mathrm{~m}$ above sea level, the atmospheric pressure will change by more than $1 \%$, in which $\mathrm{P}_{\mathrm{a}}$ can be chosen according to the annual average statistical

\footnotetext{
*Corresponding Author, E-mail: 1504730841@qq.com
} 
value of local atmospheric pressure. If this data is not available or the data source is not reliable, formula (2) is able to help to calculate $\mathrm{P}_{\mathrm{a}}$ when the altitude is less than 5000m [4].

$P_{a}=101325 \times(1-(162.1025 \times H) /(6357 \times 1000+H))^{5.256}$

In the equation, $\mathrm{P}_{\mathrm{a}}$-local average atmospheric pressure, $\mathrm{Pa}, \mathrm{H}$-local altitude, $\mathrm{m}$.

Wet and dry bulb coefficient A used to be calculated through equation below [2]:

$$
A=0.00001 \times\left(65+\frac{6.75}{v}\right)
$$

In the equation, $\mathrm{v}$ means Air velocity surround the wet bulb, unit measurement: $\mathrm{m} / \mathrm{s}$.

Equation (3) is used when $t_{a},<40^{\circ} \mathrm{C}[5]$.

Precisely, the wet and dry bulb coefficient A is not a single value function of air speed, it is a multi-parameter composite function. The main factors affecting its figure are: 1. Air speed, 2. Size and shape of wet bulb thermometer, response speed, pollution condition, structure of upper water jacket, 3. Errors caused by radiation and heat transfer.

When $\mathrm{t}_{\mathrm{a}}>40^{\circ} \mathrm{C}$, the calculation error of $\mathrm{A}$ value will increase rapidly with the increase of temperature. When $t_{a}$ reaches $70^{\circ} \mathrm{C}$, the relative difference between the calculation result of equation (3) and the experimental data ranges from $20 \%$ to $34 \%$ under different wind speed conditions [6]. Therefore, some papers have questioned this measurement method and accuracy [7-8].

The experimental data shows that: under high temperature state, the wet and dry bulb coefficient A value is significantly related to the air flow velocity $\mathrm{V}$ and the dry bulb temperature $t_{a}$ [6].

\section{Deviation analysis between experimental data and original fitting function $A\left(v, t_{a}\right)[6]$}

\subsection{Experimental data and original fitting function $A\left(v, t_{a}\right)$}

Table 1 (temperature range of $10{ }^{\circ} \mathrm{C} \leq \mathrm{t} \leq 70{ }^{\circ} \mathrm{C}$ and air flow rate of $0.02 \mathrm{~m} / \mathrm{s} \leq \mathrm{v} \leq 4.00 \mathrm{~m} / \mathrm{s}$.) The values of wet and dry bulb coefficient $A$, under different air flow velocities $v$ and dry bulb temperatures $t_{a}$, through the actual measurement of U. P. $t_{a} \cdot t_{w}$ and $v$ with high-precision instruments and meters, the data can be obtained. Then the table of spherical wet and dry bulb coefficient A can be calculated by formula (1), which is indirectly measured Experimental data table [6]. This method can reflect the parameters that affect the wet and dry bulb coefficient A macroscopically. Chart 1 shows the curve of a value data change under different $v$ and $t_{a}$ states.

The $\mathrm{A}\left(\mathrm{v}, \mathrm{t}_{\mathrm{a}}\right)$ relation proved by reference is as follows [6].

$A\left(v, t_{a}\right)=0.649 \times 10^{-3}+\frac{0.068 \times 10^{-3}}{v}+0.072 \times 10^{-3} \times t_{a}{ }^{3}$

(4)

In the equation: $\mathrm{v}$ is the velocity of air around the wet bulb, $\mathrm{m} / \mathrm{s}, \mathrm{t}_{\mathrm{a}}$ is the dry bulb temperature $\left({ }^{\circ} \mathrm{C}\right)$.
Table 1.Experimental data table of wet and dry bulb coefficient $A$ and $v, t_{a}[6]$

\begin{tabular}{|c|c|c|c|c|c|c|c|c|}
\multicolumn{10}{c|}{$\left(\mathrm{A} \times 10^{3}\right)$} \\
\hline \multicolumn{2}{|c|}{$\mathrm{V}$} & \multicolumn{7}{c|}{ Temperature $\left.\mathrm{t}_{\mathrm{a}}{ }^{\circ} \mathrm{C}\right)$} \\
\hline & $\mathrm{s} / \mathrm{m}$ & 10 & 20 & 30 & 40 & 50 & 60 & 70 \\
\hline $\mathrm{i}$ & $\mathrm{j}$ & 1 & 2 & 3 & 4 & 5 & 6 & 7 \\
\hline 1 & 0.02 & 4.030 & 4.032 & 4.041 & 4.049 & 4.110 & 4.190 & 4.297 \\
\hline 2 & 0.05 & 2.010 & 2.008 & 2.021 & 2.028 & 2.080 & 2.125 & 2.243 \\
\hline 3 & 0.10 & 1.332 & 1.332 & 1.341 & 1.357 & 1.410 & 1.490 & 1.670 \\
\hline 4 & 0.20 & 0.992 & 0.994 & 1.001 & 1.010 & 1.070 & 1.150 & 1.320 \\
\hline 5 & 0.50 & 0.801 & 0.791 & 0.802 & 0.808 & 0.871 & 0.950 & 1.130 \\
\hline 6 & 1.00 & 0.722 & 0.722 & 0.735 & 0.742 & 0.800 & 0.883 & 1.060 \\
\hline 7 & 1.20 & 0.711 & 0.713 & 0.726 & 0.731 & 0.788 & 0.881 & 1.051 \\
\hline 8 & 1.50 & 0.705 & 0.704 & 0.712 & 0.722 & 0.779 & 0.860 & 1.035 \\
\hline 9 & 2.00 & 0.696 & 0.694 & 0.703 & 0.707 & 0.768 & 0.849 & 1.032 \\
\hline 10 & 2.50 & 0.682 & 0.685 & 0.696 & 0.703 & 0.761 & 0.842 & 1.021 \\
\hline 11 & 3.00 & 0.679 & 0.678 & 0.694 & 0.700 & 0.757 & 0.838 & 1.022 \\
\hline 12 & 3.50 & 0.676 & 0.675 & 0.687 & 0.699 & 0.753 & 0.834 & 1.010 \\
\hline 13 & 4.00 & 0.670 & 0.672 & 0.686 & 0.701 & 0.751 & 0.832 & 1.011 \\
\hline
\end{tabular}

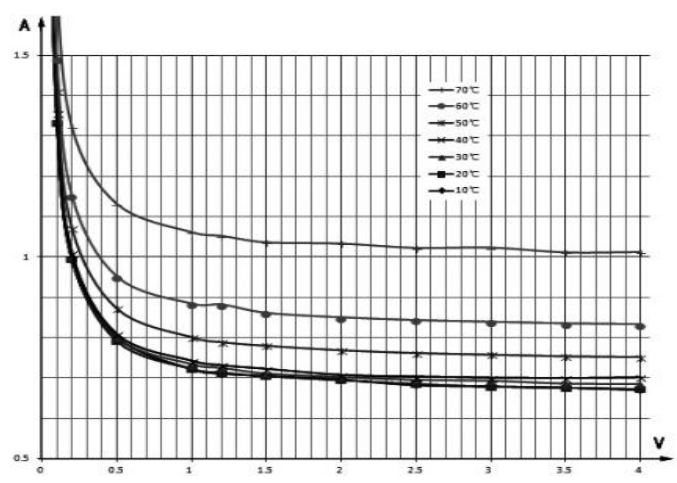

Fig.1.Curve of A-value experimental data under different $v$ and $t_{\mathrm{a}}$ States

\subsection{Deviation analysis}

Initially, the concept of degree of deviation (D.D) is introduced, which is defined as the proportion of the absolute value of the absolute difference between the actual data and the target data in the target data. Its formula (5) as follows.

$$
\text { D. } D=\left|\frac{A-X}{A}\right| \times 100 \%
$$
data.

In the equation, $\mathrm{A}$ is the target data, $\mathrm{X}$ is the actual

In this paper, the formula of deviation degree (D.D) is changed into formula (6), the relevant formula of average deviation degree (AD) and standard deviation degree (SD) are introduced.

Deviation degree $(D . D)=\left|\frac{\{A\}_{i, j}-A\left(v, t_{a}\right)_{i, j}}{\{A\}_{i, j}}\right| \times 100 \%$

Mean deviation of deviation $(A D)=$ $\frac{\Sigma \Sigma\left|(D . D)_{i, j}-\overline{(D . D)}_{i, j}\right|}{n \times k}$ 


$$
(S D)=\sqrt{\left.\frac{\sum \sum\left((D . D)_{i, j}-\overline{(D . D)}\right.}{n \times k-1}\right)^{2}}
$$

In the equation: $\{\mathrm{A}\}_{\mathrm{i}, \mathrm{j}}$ is the data of wet and dry bulb coefficient $A$ of corresponding $\mathrm{v}$ and $\mathrm{t}_{\mathrm{a}}$ in Table 1 , $A\left(v, t_{a}\right)_{i, j}$ is the data calculated according to formula (4) of $\mathrm{A}\left(\mathrm{v}, \mathrm{t}_{\mathrm{a}}\right)$ under the condition of corresponding $\mathrm{v}$ and $t_{a}$ with $A, i=1,2,3, \ldots k, j=1,2,3, \ldots n, k=13, n=7$,

It uses excel to calculate and analyze the data of each state point of a value in formula $A\left(v, t_{a}\right)(4)$ and table 1 [6]: the maximum deviation (D.D) of the data of discovery formula (4) and table 1 is $2345.21 \%$, and the minimum is $3.71 \%$, the comparative analysis of 91 specific data shows that: 86 data with deviation (D.D) greater than $15 \%$, the average deviation (AD) of deviation degree is 6.438 , and the standard deviation (SD) of deviation degree is 7.575 .

From the data analysis above, it is shown that the original fitting function A $\left(v, t_{a}\right)$, formula (4) has a very large deviation, and the structure of formula (4) has an issue of imbalance, which needs to be further corrected.

\section{Improvement method and establishment of new calculation model}

\subsection{Linear interpolation method to obtain the wet and dry bulb coefficient $A$ under the given conditions of $v$ and $t_{a}$}

This method is relatively simple and practical. Table 1 [6] can be used as the basic data table, then the wet and dry bulb coefficient a under the given $V$ and $t_{a}$, conditions is able to calculated through linear interpolation method with equation (9).

$$
Y=Y_{1}+\frac{Y_{2}-Y_{1}}{X_{2}-X_{1}} \times\left(X-X_{1}\right)
$$

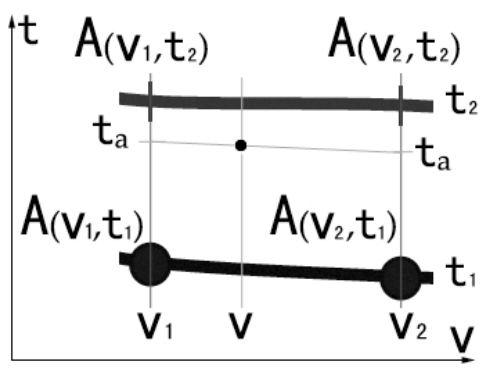

Fig.2.Position coordinate diagram of linear interpolation method

According to the definition of linear interpolation method, the data of A-value of wet and dry bulb coefficient of non-node in Table 1 can be calculated by linear interpolation method (9) [6], and up to three times, it can calculate the corresponding value of A-value of wet and dry bulb coefficient $\mathrm{A}\left(\mathrm{v}, \mathrm{t}_{\mathrm{a}}\right)$ in the definition domain $\left(10{ }^{\circ} \mathrm{C} \leq \mathrm{t}_{\mathrm{a}}, \leq 70{ }^{\circ} \mathrm{C}, 0.02 \mathrm{~m} / \mathrm{s} \leq \mathrm{v} \leq 4 \mathrm{~m} / \mathrm{s}\right)$. Chart 2 is the position coordinate diagram of linear interpolation method, and the corresponding interpolation evolution formula is as follows:

$A\left(v_{1}, t_{a}\right)=A\left(v_{1}, t_{1}\right)+\frac{t_{a}-t_{1}}{t_{2}-t_{1}} \times\left(A\left(v_{1}, t_{2}\right)-\right.$
$\left.A\left(v_{1}, t_{1}\right)\right)(10)$

$A\left(v_{2}, t_{a}\right)=A\left(v_{2}, t_{1}\right)+\frac{t_{a}-t_{1}}{t_{2}-t_{1}} \times\left(A\left(v_{2}, t_{2}\right)-A\left(v_{2}, t_{1}\right)\right)$

(11)

$A\left(v, t_{a}\right)=A\left(v_{1}, t_{a}\right)+\frac{t_{a}-t_{1}}{t_{2}-t_{1}} \times\left(A\left(v_{2}, t_{a}\right)-A\left(v_{1}, t_{a}\right)\right)$

(12)

E.g. A $(0.70,45)$ can be calculated under the given value $\mathrm{v}=0.7 \mathrm{~m} / \mathrm{s}, \mathrm{t}_{\mathrm{a}}=45^{\circ} \mathrm{C}$.

In accordance with Chart 1 , it can find out $\mathrm{A}$ $(0.50,40), \mathrm{A}(0.50,50)[6]$,

$\mathrm{A}\left(\mathrm{v}_{1}, \mathrm{t}_{1}\right)=\mathrm{A}(0.50,40)=0.808 \times 10^{-3}, \mathrm{~A}\left(\mathrm{v}_{1}, \mathrm{t}_{2}\right)=\mathrm{A}$ $(0.50,50)=0.871 \times 10^{-3}$,

Take those into formula 10 , it comes to $A\left(v_{1}, t_{a}\right)=A$ $(0.50,45)=0.840 \times 10^{-3}$,

In accordance with Chart 1 [1], it can also find out $\mathrm{A}$ $(1.00,40), \mathrm{A}(1.00,50)$,

$A\left(v_{2}, t_{1}\right)=A(1.00,40)=0.742 \times 10^{-3}, A\left(v_{2}, t_{2}\right)=A$ $(1.00,50)=0.800 \times 10^{-3}$,

Take those into formula 11 , it comes to $A\left(v_{2}, t_{a}\right)=A$ $(1.00,45)=0.771 \times 10^{-3}$,

Take A $(0.50,45), A(1.00,45)$ into formula 12 ,

$\mathrm{A}\left(\mathrm{v}, \mathrm{t}_{\mathrm{a}}\right)=\mathrm{A}(0.70,45)=\left(\mathrm{A}\left(\mathrm{v}_{1}, \mathrm{t}_{\mathrm{a}}\right)+\frac{\mathrm{v}-\mathrm{v}_{1}}{\mathrm{v}_{2}-\mathrm{v}_{1}} \times\left(\mathrm{A}\left(\mathrm{v}_{2}, \mathrm{t}_{\mathrm{a}}\right)\right.\right.$ $\left.\left.-\mathrm{A}\left(\mathrm{v}_{1}, \mathrm{t}_{\mathrm{a}}\right)\right)\right) \times 10-3=0.812 \times 10^{-3}$

The advantage of this method is that it is very convenient to use Excel for interpolation calculation under given conditions. However, if it is used for data flow calculation processing, or programming calculation, is not convenient, and the calculation takes long steps.

\subsection{Calculation method and establishment of new calculation model}

\subsubsection{Design of new calculation method}

Under the condition of ensuring multiple constraint functions, especially the theory of error minimization method is used as the constraint function, the system model is set as a rational function for approximation [9], which is an ideal solution to find the fitting approximation function $\widehat{\mathrm{A}}\left(\mathrm{v}, \mathrm{t}_{\mathrm{a}}\right)$.

$$
Y=\min _{\hat{A}\left(v_{i}, t_{a j}\right)} \sum_{i=1}^{k} \sum_{j=1}^{n}\left|A\left(v_{i}, t_{a j}\right)-\hat{A}\left(v_{i}, t_{a j}\right)\right|
$$

In the equation: $\mathrm{Y}$ is the minimum error function, $\mathrm{A}\left(\mathrm{v}_{\mathrm{i}}, \mathrm{t}_{\mathrm{aj}}\right)$ is the original function, $\widehat{\mathrm{A}}\left(\mathrm{v}_{\mathrm{i}}, \mathrm{t}_{\mathrm{aj}}\right)$ is the new fitting approximation function.

The method above is able to be evolved to control the minimum value of deviation degree (D.D). The smaller the deviation degree (D.D) is, the higher the precision of fitting approximation function is getting, and vice versa.

The design of this method aims to establish objective function model and constraint condition function, and to obtain a new fitting approximation function $\widehat{A}\left(v_{i}, t_{a j}\right)$ by iterative approximation of search method [10].

\subsubsection{Found of new calculation model}

Under the condition of standard atmospheric pressure, in order to analyze formula (1) of measuring $U$ by wet and dry bulb method, when the deviation degree (D.D) is less than $2 \%$, the possible calculation deviation for $U$ will be 
less than $0.5 \%$, which is enough to meet the accurate requirements of measuring $U$ by wet and dry bulb method. (Notice: the allowable range of indication error of the dry and wet meter used in the work is $\pm 5 \%$ R.H) [2].

Therefore, to find a new fitting approximation function $\widehat{A}\left(v_{i}, t_{a j}\right)$, to ensure that the deviation (D.D) 'value of all the experimental data in Table 1 is less than $2 \%$, this problem can be solved [6].

$$
(D . D)^{\prime}=\left|\frac{\{A\}_{i, j}-\hat{A}\left(v, t_{a}\right)_{i, j}}{\{A\}_{i, j}}\right| \times 100 \%
$$

In the equation: $\{\mathrm{A}\}_{\mathrm{i}, \mathrm{j}}$ is the corresponding experimental data in Table $1, \widehat{A}\left(v, t_{a}\right)_{i, j}$ is the calculated value of the new fitting approximation function $\widehat{A}\left(v, t_{a}\right)$ under the condition of $\mathrm{v}$ [6], $\mathrm{t}_{\mathrm{a}}$ corresponding to $\mathrm{a}$ in Table 1 [6], in which: $i=3,4,5, \ldots k, j=1,2,3, \ldots n$, $\mathrm{k}=13, \mathrm{n}=7$.

According to the two-dimensional function approximation theory [11], the numerical distribution law in Table 1 conforms to the condition that the separated variables (in which the variable $\mathrm{v}$ is the main variable), so its structure can be greatly simplified. This calculation model is based on the image characteristic curve made by equation (4) and the curve 2 made by experimental data table 1 [6], using the relevant constraint function conditions and the function step-by-step superposition, through'Linear search', iterative approximation, to find new function expression that can meet the accuracy requirements, establish a new fitting approximation function $\widehat{A}\left(v, t_{\mathrm{a}}\right)$ model.

Establishment of objective function model:

$\hat{A}\left(v, t_{a}\right)=\left(a+\frac{b}{v}-c \times t_{a}{ }^{2}+d \times t_{a}{ }^{3}+10^{\left(e \times t_{a}-f\right)}\right) \times 10^{-3}(15)$

In the equation: $\mathrm{a}, \mathrm{b}, \mathrm{c}, \mathrm{d}, \mathrm{e}, \mathrm{f}$ are the coefficient values to be determined, $t_{a}$ is the dry bulb temperature $\left(10{ }^{\circ} \mathrm{C} \leq \mathrm{t}_{\mathrm{a}}, \leq 70{ }^{\circ} \mathrm{C}\right), \mathrm{V}$ is the air velocity around the wet bulb $(0.1 \mathrm{M} / \mathrm{s} \leq \mathrm{V} \leq 4 \mathrm{~m} / \mathrm{s})$.

Constraint function:

Deviation degree (D.D)':

$\left|\frac{\{A\}_{i, j}-\hat{A}\left(v, t_{a}\right)_{i, j}}{\{A\}_{i, j}}\right| \times 100 \%<2.0$

Mean deviation $(\bar{X}): \frac{\sum_{i=1}^{k} \sum_{j=1}^{n}\left|(D . D)^{\prime} i, j\right|}{(k-2) \times n}<0.70 \%$

Mean deviation of deviation $(A D)$ :

$\frac{\sum \sum \mid(D . D)^{\prime} i, j-\overline{(D . D)^{\prime}} i, j}{(k-2) \times n}<0.35 \%$

Standard deviation of deviation (SD):

$\sqrt{\frac{\sum \sum\left((D . D)^{\prime} i, j-\overline{(D . D)^{\prime}} i, j\right)^{2}}{((k-2) \times n)-1}}<0.45 \%$

In the equation, $\mathrm{i}=3,4,5, \ldots \mathrm{k}, \mathrm{j}=1,2,3, \ldots \mathrm{n}, \mathrm{k}=13, \mathrm{n}=7$,

Through programming operation and data analysis of array by Excel, the coefficients of fitting approximation function $\widehat{A}\left(v, t_{a}\right)$ ) that can meet the constraint function conditions are obtained. The specific coefficients are as follows:

$\mathrm{a}=0.65275, \mathrm{~b}=0.0675, \mathrm{c}=-1.9655 \times 10^{-5}$,

$\mathrm{d}=1.006 \times 10^{-6}, \mathrm{e}=0.0945, \mathrm{f}=7.67$,

Take all values into formula 20 .

$$
\hat{A}\left(v, t_{a}\right)=10^{-3} \times\left(0.65275+\frac{0.0675}{v}-1.9655 \times 10^{-5} \times t_{a}{ }^{2}+\right.
$$

$\left.1.006 \times 10^{-6} \times t_{a}^{3}+10^{\left(0.0945 \times t_{\mathrm{a}}-7.67\right)}\right)$

After the simplification, it comes to formula (21).

$\hat{A}\left(v, t_{a}\right)=10^{-5} \times\left(65.275+\frac{6.75}{v}-1.9655 \times 10^{-3} \times t_{a}^{2}+1.0\right.$ $\left.06 \times 10^{-4} \times t_{a}{ }^{3}+10^{\left(0.0945 \times t_{a}-5.67\right)}\right)(21)$

\section{Deviation analysis of $\widehat{A}\left(v, t_{a}\right)$-formula (21)}

\subsection{Deviation analysis of new fitting approximation function a $\widehat{A}\left(v, t_{a}\right)$ formula (21) and experimental data table 1 [6]}

5.1 .1 In the range of $0.02 \mathrm{~m} / \mathrm{s} \leq v \leq 0.05 \mathrm{~m} / \mathrm{s}, 10^{\circ} \mathrm{C}$ $\leq t_{a}, \leq 70^{\circ} \mathrm{C}$, the deviation analysis of the new function $\hat{A}\left(v, t_{a}\right)$-formula (21) and table 1 [6]

The range of $10^{\circ} \mathrm{C} \leq \mathrm{t}_{\mathrm{a}} \leq 70^{\circ} \mathrm{C}, \quad 0.02 \mathrm{~m} / \mathrm{s} \leq \mathrm{v} \leq 0.05 \mathrm{~m} / \mathrm{s}$ is the check area defined for the existed function $\widehat{A}\left(v, t_{a}\right)$ in order to verify the applicability of the new function $\widehat{\mathrm{A}}\left(\mathrm{v}, \mathrm{t}_{\mathrm{a}}\right)$ formula (21) and the deviation degree (D.D)' data compared with chart 1 in the non defined area are shown in chart $2(\%)[6]$ :

When $\mathrm{v}=0.05 \mathrm{~m} / \mathrm{s}, \mathrm{t}_{\mathrm{a}}=70^{\circ} \mathrm{C}$, the deviation degree is relatively large, reaching $4.307 \%$, and the deviation degree of the other 13 points are between $0.080 \%$ and $1.614 \%$. The data show that the new function $\widehat{A}\left(v, t_{a}\right)$ formula (21) fits the chart 1.

Table 2. Deviation degree (D.D)' data of comparison between new function $\widehat{A}\left(v, t_{a}\right)$ and data $(\%)$ table 1 in undefined area.

\begin{tabular}{|c|c|c|c|c|c|c|c|}
\hline $\mathrm{V}$ & \multicolumn{7}{|c|}{ Temperature $\mathrm{t}_{\mathrm{a}}\left({ }^{\circ} \mathrm{C}\right)$} \\
\hline $\mathrm{s} / \mathrm{m}$ & 10 & 20 & 30 & 40 & 50 & 60 & 70 \\
\hline 0.02 & 0.08 & 0.101 & 0.093 & 0.292 & 0.11 & 0.136 & 1.573 \\
\hline 0.05 & 0.408 & 0.252 & 0.434 & 0.385 & 0.024 & 1.614 & 4.307 \\
\hline
\end{tabular}

5.1.2 In the range of $0.1 \mathrm{~m} / \mathrm{s} \leq v \leq 4 \mathrm{~m} / \mathrm{s}, 10^{\circ} \mathrm{C} \leq t_{a} \leq 70^{\circ} \mathrm{C}$, the deviation analysis of the new function $\hat{A}\left(v, t_{a}\right)$ formula (21) and table 1[6]

Take the corresponding conditions $\mathrm{V}$ and $\mathrm{t}_{\mathrm{a}}$ in Table 1 into formula (21) [6], compared with the data in Table 1 [6], it calculates the deviation degree (D.D)' data (\%) is shown in table 3, it's shown that:

The maximum deviation degree (D.D)' is $1.777 \%$, among them, there are 16 points in the deviation degree (D.D)' from $1 \%$ to $1.777 \%$, and 61 points in the deviation degree (D.D)' from $0.0 \%$ to $1.0 \%$, the average deviation degree $(\overline{\mathrm{X}})$ in the definition domain is $0.678 \%$, the average deviation degree (AD) is $0.342 \%$, and the standard deviation degree (SD) is $0.434 \%$.

All the data above meet the constraint function formula (16), formula (17), formula (18), formula (19). The data show that the new function $\widehat{\mathrm{A}}\left(\mathrm{v}, \mathrm{t}_{\mathrm{a}}\right)$ fit the experimental data table 1 well [6].

Table 3. Deviation degree (D.D)' data of comparison between new function $\widehat{A}\left(\mathrm{v}, \mathrm{t}_{\mathrm{a}}\right)$ and data $(\%)$ table 1 in definition area [6] 


\begin{tabular}{|c|c|c|c|c|c|c|c|}
\hline $\mathrm{V}$ & \multicolumn{7}{|c|}{ Temperature $\mathrm{t}_{\mathrm{a}}\left({ }^{\circ} \mathrm{C}\right)$} \\
\hline $\mathrm{s} / \mathrm{m}$ & 10 & 20 & 30 & 40 & 50 & 60 & 70 \\
\hline 0.10 & 0.391 & 0.305 & 0.281 & 0.281 & 0.319 & 0.383 & 0.323 \\
\hline 0.20 & 0.273 & 0.358 & 0.126 & 1.318 & 0.187 & 0.279 & 0.538 \\
\hline 0.50 & 1.774 & 0.387 & 0.594 & 1.586 & 0.632 & 0.601 & 0.478 \\
\hline 1.00 & 0.375 & 0.216 & 0.716 & 1.525 & 0.250 & 0.704 & 0.273 \\
\hline 1.20 & 0.416 & 0.535 & 1.035 & 1.514 & 0.159 & 1.755 & 0.490 \\
\hline 1.50 & 1.164 & 0.861 & 0.669 & 1.221 & 0.450 & 0.664 & 0.038 \\
\hline 2.00 & 1.503 & 1.054 & 0.998 & 1.777 & 0.489 & 0.702 & 0.838 \\
\hline 2.50 & 0.471 & 0.739 & 0.972 & 1.396 & 0.460 & 0.678 & 0.431 \\
\hline 3.00 & 0.694 & 0.378 & 1.335 & 1.188 & 0.529 & 0.741 & 0.968 \\
\hline 3.50 & 0.728 & 0.411 & 0.797 & 0.873 & 0.427 & 0.651 & 0.110 \\
\hline 4.00 & 0.199 & 0.325 & 1.004 & 0.241 & 0.483 & 0.702 & 0.447 \\
\hline
\end{tabular}

\subsection{Deviation analysis of new fitting approximation function $\widehat{A}\left(v, t_{a}\right)$ formula (21) and formula}

Equation (2) is a classical calculation formula of dry wet bulb coefficient A. In order to further verify the consistency of the new fitting approximation function $\widehat{\mathrm{A}}\left(\mathrm{v}, \mathrm{t}_{\mathrm{a}}\right)$ equation (21) and equation (2), the expression (22) of deviation degree (D.D)" is redefined here.

$$
(D . D)^{\prime \prime}=\left|\frac{\hat{A}\left(v, t_{a}\right)_{i, j}-A(v)_{i, j}}{\hat{A}\left(v, t_{a}\right)_{i, j}}\right| \times 100 \%
$$

In the equation, $\mathrm{i}=1,2,3, \ldots \mathrm{k}, \mathrm{j}=1,2,3, \ldots \mathrm{n}$, $\mathrm{k}=13, \mathrm{n}=5$, formula $(2) A(v)_{i, j}$ has no relationship with $t_{a}$.

Table 4 shows the deviation degree (D.D)" data (\%) obtained by comparing the new function $\widehat{A}\left(v, t_{a}\right)$ formula (21) with formula (3), and the data analysis in Table 4 shows that:

In the range of $10^{\circ} \mathrm{C} \leq \mathrm{t}_{\mathrm{a}} \leq 30^{\circ} \mathrm{C}, 0.02 \mathrm{~m} / \mathrm{s} \leq \mathrm{v} \leq 4.0 \mathrm{~m} / \mathrm{s}$, the maximum deviation (D.D)" is $1.906 \%$, hense, the new function $\widehat{A}\left(v, t_{a}\right)$ fit this region well.

When $30^{\circ} \mathrm{C}<\mathrm{t}_{\mathrm{a}}$, it is found that the deviation degree (D.D)" will increase with the increase of $t_{a}$ and $V$. When $\mathrm{t}_{\mathrm{a}}=70^{\circ} \mathrm{C}$, the maximum deviation degree (D.D)" will exceed $33 \%$. It is further proved that formula (3) is only suitable for the environment within $t_{a}<40^{\circ} \mathrm{C}$.

Table 4. Table of deviation degree (D.D)" data obtained by comparing the new function $\widehat{A}\left(v, t_{a}\right)$ with formula (2)

\begin{tabular}{|c|c|c|c|c|c|c|}
\hline \multicolumn{2}{|c|}{$\mathrm{v}$} & \multicolumn{5}{|c|}{ Temperature $\mathrm{t}_{\mathrm{a}}\left({ }^{\circ} \mathrm{C}\right)$} \\
\hline & $\mathrm{s} / \mathrm{m}$ & 10 & 20 & 30 & 40 & 50 \\
\hline $\mathrm{i}$ & $\mathrm{j}$ & 1 & 2 & 3 & 4 & 5 \\
\hline 1 & 0.02 & $0.05 \%$ & $0.07 \%$ & $0.30 \%$ & $0.89 \%$ & $1.95 \%$ \\
\hline 2 & 0.05 & $0.10 \%$ & $0.15 \%$ & $0.60 \%$ & $1.77 \%$ & $3.85 \%$ \\
\hline 3 & 0.10 & $0.15 \%$ & $0.23 \%$ & $0.90 \%$ & $2.65 \%$ & $5.69 \%$ \\
\hline 4 & 0.20 & $0.10 \%$ & $0.20 \%$ & $1.20 \%$ & $3.42 \%$ & $7.49 \%$ \\
\hline 5 & 0.50 & $0.25 \%$ & $0.38 \%$ & $1.51 \%$ & $4.39 \%$ & $9.25 \%$ \\
\hline 6 & 1.00 & $0.14 \%$ & $0.28 \%$ & $1.64 \%$ & $4.65 \%$ & $10.03 \%$ \\
\hline 7 & 1.20 & $0.28 \%$ & $0.42 \%$ & $1.67 \%$ & $4.85 \%$ & $10.29 \%$ \\
\hline 8 & 1.50 & $0.29 \%$ & $0.43 \%$ & $1.70 \%$ & $4.93 \%$ & $10.32 \%$ \\
\hline 9 & 2.00 & $0.29 \%$ & $0.44 \%$ & $1.72 \%$ & $5.00 \%$ & $10.47 \%$ \\
\hline
\end{tabular}

\begin{tabular}{|l|l|l|l|l|l|l|}
\hline 10 & 2.50 & $0.30 \%$ & $0.44 \%$ & $1.74 \%$ & $5.05 \%$ & $10.57 \%$ \\
\hline 11 & 3.00 & $0.15 \%$ & $0.30 \%$ & $1.75 \%$ & $4.94 \%$ & $10.62 \%$ \\
\hline 12 & 3.50 & $0.30 \%$ & $0.45 \%$ & $1.91 \%$ & $5.11 \%$ & $10.80 \%$ \\
\hline 13 & 4.00 & $0.30 \%$ & $0.45 \%$ & $1.77 \%$ & $5.12 \%$ & $10.71 \%$ \\
\hline
\end{tabular}

\section{Conclusions}

The analysis above shows that the wet and dry bulb coefficient $\mathrm{A}$ is not only related to the wind speed $\mathrm{v}$, but also to the ambient temperature $t_{a}$. Especially in the high temperature area, the wet and dry bulb coefficient A will decrease with the temperature increase, which will expand the error between the traditional calculation and the actual situation. In the middle and high altitude, low pressure working areas, the influence is even greater, up to $20 \%$ R.H error. Hence, considering the influence of wind speed and ambient temperature on the wet and dry bulb coefficient $\mathrm{A}$, the wet and dry bulb method is getting more practical. It has positive impact on the environmental control of industrial and agricultural production in the new era, and achieve high-precision environmental state control through relatively low-cost moisture measuring device [12].

The new fitting approximation function $\widehat{A}\left(v, t_{a}\right)$ formula $(21)$ in this paper is not a unique relation expression. It is only a kind of expression function satisfying the constraints.

The new fitting approximation function $\widehat{A}\left(v, t_{a}\right)$ formula (21), in the range of $0.1 \mathrm{~m} / \mathrm{s} \leq \mathrm{v} \leq 4 \mathrm{~m} / \mathrm{s}, 10^{\circ} \mathrm{C} \leq \mathrm{t}_{\mathrm{a}} \leq 70^{\circ} \mathrm{C}$, has enough high accuracy. Without considering other interference effects, such as temperature measurement, pressure measurement and speed measurement, the accuracy error of relative humidity measurement by dry wet ball method is less than $0.5 \%$.

\section{References}

1. Feng H-m: Development of the date shifter of multi-channel relative humidity testing. Journal of Zhejiang Textile \& Fashion College 2006:54-58.

2. Liang $X-Z$, Zhang $J$ : Discussion on the measurement of humidity by wet and dry bulb method. Measurement Technique 2007:68-69.

3. Chen Y-s: The an example of wind speed revise and air pressure revise for relative humidity measure date. Environment alapaptability\& reliability 2007:14-17.

4. Northwest electric power design institute CO. Locpecg: Technical code for design and calculation of combustion system of fossil-fired power plant: DL/T 5240-2010. Beijing: China Electric Power Press; 2011.

5. Zhu L-k, Wen X-q: The Elements of Hygrometry and Addition Error of Norm Aspirated Psychrometer. Modern measurement and test 2001:37-39+33. 
6. Huang X-y, Zhou P: Method for calculating relative humidity in flue-cured tobacco chamber. Transactions of the CSAE 2006:164-166.

7. Sauer HJ, Nelson HF, Xian-hong H: The search for high temperature experimental psychrometric data. ASHRAE Transactions 2001, 107:768-779.

8. M LE, M RJ, F MJ: Potential for evaporative cooling during heat stress periods in pig production in Portugal ( Alentejo). Journal of Agricul-tural Engineering Research 2000, 76:363-371.

9. Zuo $X$, Zhuang $X, X u$ J, Tan Z-Z: Rational Function Approximation Method for Fractional Order System Based on Linear Programming. Information and Control 2014, 43:697-704+710.

10. Chen Y-s: Mathematical Formula for Resolving the Relation between $A$ and V. Equipment environmental engineering 2006:37-40.

11. Xu X-y, Li J-k: Pad'e Approximation probability. Shanghai: Shanghai Scientific \& Technical Publishers; 1990.

12. Feng Q-s, Chen L-f, Wang X-h, Le Y-n, Zheng J: Application and Analysis of water ring vacuum pumps reform Based on Characteristic Curve. In 2019 2nd InternationConfernce on Maufacturing Technology, Materials and Chemical Engineering, MTMCE 2019. Wuhan, China: Institute of Physics Publishing; 2019. 